\title{
RANDOMIZED PROSPECTIVE STUDY COMPARING TRANSVERSE AND EXTRACORTICAL FIXATION IN ANTERIOR CRUCIATE LIGAMENT RECONSTRUCTION
}

Eduardo da Silva Guarilha', Paulo Roberto de Andrade Fígaro Caldeira', Ozorio de Almeida Lira Neto², Marcelo Schmidt Navarro $^{3}$, Antonio Milani ${ }^{4}$, Mario Carneiro Filho 5

\section{ABSTRACT}

Objective: This study had the objective of prospectively comparing transverse fixation (Cross-Pin ${ }^{\mathrm{TM}}$ ) with extracortical fixation $\left(E_{2 L o c}{ }^{\mathrm{TM}}\right)$ for the femur, in surgical reconstruction of the anterior cruciate ligament, from a clinical, biomechanical and functional point of view. Methods: Between April 2007 and November 2009,50 patients with acute or chronic anterior cruciate ligament injuries underwent arthroscopic reconstruction using the homologous flexor tendons (gracilis and semitendinosus). Randomization of the femoral fixation method was done by means of a draw at the time of the procedure. Patients were excluded if they presented multiple ligament lesions, fractures, previous surgery, autoimmune disease and impairment of the contralateral knee. The Lysholm scale, SF36 quality-of-life questionnaire and $\mathrm{KT} 1000^{\mathrm{TM}}$ arthrometer were used. Results: After a mean follow-up of 18.1 months, there were no statistically significant differences between the groups regarding the Lysholm scale and KT1000 ${ }^{\mathrm{TM}}$ measurements. However, the SF36 questionnaire showed a statistical difference such that transverse fixation was superior regarding pain and vitality. Conclusion: Both techniques were shown to be efficient for transfemoral fixation, but with almost no statistically significant difference between them. We believe that new studies will be necessary for better understanding of these differences.

Keywords - Anterior Cruciate Ligament; Arthroscopy; Prospective Studies

\section{INTRODUCTION}

The number of new injuries of the anterior cruciate ligament (ACL) has been increasing significantly year by year, because of torsional sports trauma and high-energy accidents. Some authors have reached the estimate that 36 new cases occur per 100,000 inhabitants per year ${ }^{(1-3)}$.

Over the last decade, ACL reconstruction surgery by means of arthroscopy has become routine. Reconstruction using the semitendinosus and gracilis flexor tendons has the objective of promoting reestablishment of joint stability and making it possible for the individual to return to the same functional level and quality of life as before the injury, with a minimum of incapacity or restriction ${ }^{(1,4)}$.
Good and excellent results with follow-ups of 10 years or more have been seen through rates ranging from 75 to $95 \%$, taking into consideration stability, symptom relief and the possibility of returning to sports ${ }^{(1-3,5-7)}$.

With regard to replacements for the ACL, autologous grafts can be considered to be the first choice for ligament reconstruction. The grafts most used are the tendons of the flexor muscles (semitendinosus and gracilis) and the patellar ligament. Although the latter is much used, it presents a series of complications in the donor region, such as patellar tendinitis or patellofemoral arthrosis ${ }^{(4,8)}$. Security of graft fixation in the bone tunnels is the crucial point in ACL reconstruction surgery, since this represents restoration of

1 - Resident Physician at IFOR Hospital, São Bernardo do Campo, SP, Brazil.

2 - Orthopedist in the Knee Group, Department of Orthopedics and Traumatology, Federal University of São Paulo (Unifesp), São Paulo, SP, Brazil.

3 - Orthopedist in the Sports Traumatology Group, Discipline of Orthopedics, ABC School of Medicine (FMABC), Santo André, SP, Brazil.

$4-\mathrm{PhD}$ in Orthopedics and Traumatology from the Federal University of São Paulo (Unifesp), São Paulo, SP, Brazil.

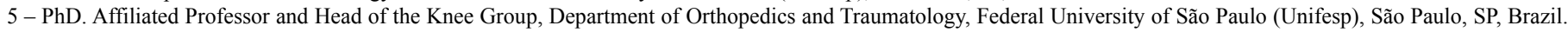

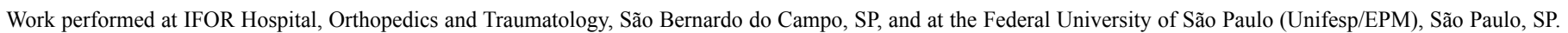
Correspondence: Antonio Milani, Rua Américo Brasiliense 596, Center, 09715-021 São Bernardo do Campo, SP. E-mail: pilot@osite.com.br Work received for publication: July 20, 2011; accepted for publication: September, 8, 2011.

The authors declare that there was no conflict of interest in conducting this work 
stability after the knee operation, thereby avoiding loosening or micromovement of the grafts, which could promote laxity prior to attainment of biological integration $^{(2,5,6,9,10)}$.

Among the graft fixation methods, there are some that use interference screws made of metal or bioabsorbable materials (poly-L-lactate acid), which are generally used in an intra-articular manner in the femur ${ }^{(10)}$. There are other methods in which use of screws, transverse pins or extracortical anchorage devices like EZLoc $^{\mathrm{TM}(11)}$ and Endobutton ${ }^{\mathrm{TM}}$ are recommended.

As can be seen, there is no definition in cases of reconstruction of ACL injuries of the knee regarding what would be the best fixation method for semitendinosus and gracilis grafts in the femur. Therefore, we developed the present randomized prospective study with the aim of comparatively evaluating the transverse femoral stabilization provided by a tradition fixation system (Cross-Pin ${ }^{\mathrm{TM}}$ ) versus an extracortical anchorage device (EZLoc ${ }^{\mathrm{TM}}$ ), taking into consideration the patient's clinical and biomechanical stability and functional capacity.

\section{MATERIAL AND METHODS}

Between April 2007 and November 2009, 50 patients with a diagnosis of ACL injuries of the knee (either acute or chronic) who were being followed up as outpatients underwent reconstruction of the injured ligament by means of arthroscopic surgery. The ipsilateral autologous flexor tendons of the gracilis and semitendinosus muscles were used as quadruple grafts.

The patients were divided into two groups of 25 individuals each, and the randomization for this took place by means of a draw that was held at the time that the patients underwent induction of anesthesia. The first group was formed by patients who underwent reconstruction in which the femoral fixation was achieved using a transfemoral device (Crosspin ${ }^{\mathrm{TM}}$ ), and the second by individuals whose stabilization was achieved using an extracortical device (EZLoc $\left.{ }^{\mathrm{TM}}\right)$. Our sample consisted of 50 patients, of whom 46 were male and four were female. Their mean age was 34.04 years, ranging from 13 to 57 years. Regarding the side affected, 27 cases were on the right side and 23 on the left side. The mean length of follow-up was 18.1 months, ranging from 10 to 40 months (Table 1).

We excluded individuals with multiple ligament lesions, associated fractures, previous surgery in the
Table 1 - Characterization of the sample.

\begin{tabular}{c|c}
\hline Variables & $\mathbf{n}=\mathbf{5 0}$ \\
\hline Age (years) - mean (sd) & $34.1(11.03)$ \\
\hline minimum - maximum & $13-57$ \\
\hline Sex - $\mathbf{n ~ ( \% ) ~}$ & $4(8)$ \\
\hline Female & $46(92)$ \\
\hline Male & \\
\hline Side operated - $\mathbf{n}(\%)$ & $27(54.0)$ \\
\hline Right & $23(46.0)$ \\
\hline Left & $33(66)$ \\
\hline Associated lesions $-\mathbf{n ~ ( \% ) ~}$ & $14(28)$ \\
\hline None & $3(6)$ \\
\hline With meniscal lesion & \\
\hline With meniscal and chondral lesions & $31(62)$ \\
\hline Trauma mechanism $-\mathbf{n}$ (\%) & $12(24)$ \\
\hline Soccer & $4(8)$ \\
\hline Martial arts & $3(6)$ \\
\hline Volleyball & \\
\hline Others & \\
\hline
\end{tabular}

affected knee, autoimmune diseases and lesions in the contralateral limb. Acute or chronic meniscal lesions were not considered to be excluding factors.

The patients in this study underwent a preoperative clinical assessment, and the Lysholm questionnaire was applied. For diagnostic purposes, radiographic and magnetic resonance imaging examinations were also performed. The data analysis and surgical procedures were performed by the same team of orthopedists.

The surgical technique for reconstruction consisted of creating tibial and femoral bone tunnels with the respective guides. In the femur, the tunnels were made in accordance with the technique of isometric reconstruction: at between 10 and 11 o'clock in the right knees and at between one and two o'clock in the left knees. The femoral fixation in the first group was performed using a transverse fixation system with bioabsorbable material (Cross-Pin ${ }^{\mathrm{TM}}$ ) (Figure 1). In the second group, the femoral fixation was done using an extracortical anchoring device (EZLoc ${ }^{\mathrm{TM}}$ ) (Figure 2). The remainder of the technique was similar in the two groups. The tibial fixation was done using an absorbable interference screw.

During the postoperative period, we followed a rehabilitation protocol in which walking with crutches was allowed after 15 days, with partial weight-bearing. Physiotherapy was continued for approximately six months. The data obtained were subjected to statistical 


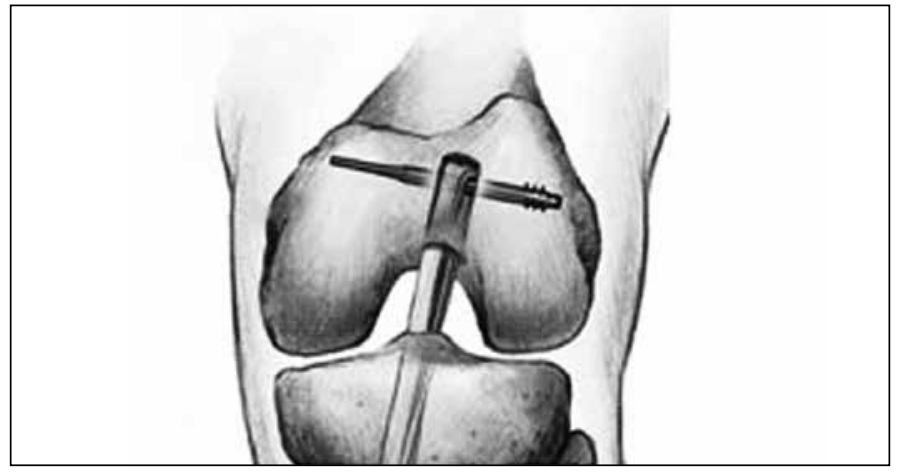

Figure 1 - Cross-Pin ${ }^{\top \mathrm{M}}$ transfemoral fixation.

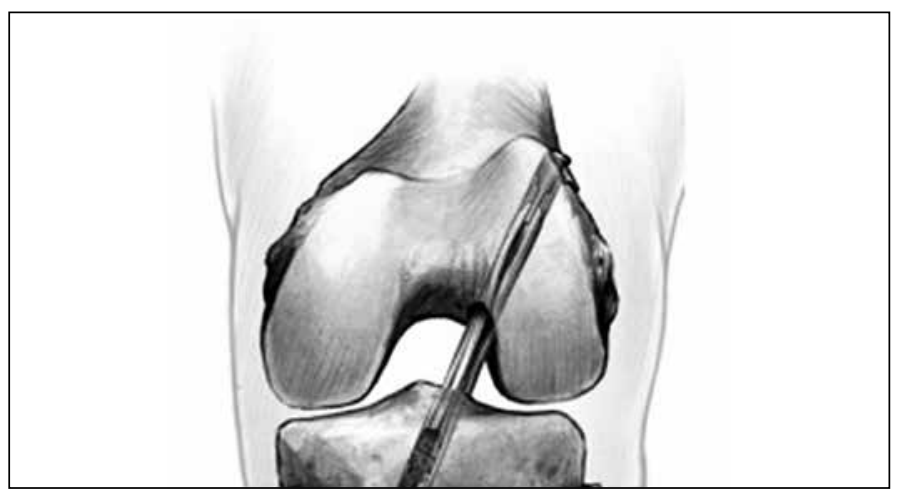

Figure 2 - EZLoc ${ }^{\mathrm{TM}}$ transfemoral fixation.

analysis, by means of Student's t test, the chi-square test and the nonparametric Mann-Whitney test.

After six months of postoperative follow-up, the Lysholm questionnaire was again applied. At the last assessment, the patients gave responses to the SF-36 quality-of-life questionnaire and underwent biomechanical tests using the KT-1000 ${ }^{\mathrm{TM}}$ arthrometer. In this test, we took differences greater than three between the operated and non-operated knees to mean that the result was poor.

\section{RESULTS}

Regarding the Lysholm questionnaire, the absolute pre and postoperative values were divided according to the technique used (Table 2).

Regarding the evaluation using the KT-1000 ${ }^{\mathrm{TM}}$ arthrometer, the third measurement at each patient's final follow-up consultation was used. Results in which the difference between the operated and non-operated knees was less than or equal to three were considered to be good, and the results were also compared between the two different techniques (Tables 3 and 4). Neither of the comparisons showed statistically significant differences, and both groups achieved high rates of good results.
Table 2 - Lysholm scale.

\begin{tabular}{l|c|c|c|c|c}
\hline & Mean & sd & Median & Minimum & Maximum \\
\hline Before operation - Total & 66.90 & 66.90 & 70 & 73.50 & 23 \\
\hline After operation - Total & 92.80 & 92.80 & 93 & 94.00 & 71 \\
\hline Group 1 - Before operation & 72.48 & 16.16 & 75 & 75.00 & 28.00 \\
\hline Group 1 - After operation & 92.52 & 6.69 & 93 & 93.00 & 76.00 \\
\hline Group 2 - Before operation & 61.32 & 21.75 & 63 & 63.00 & 23.00 \\
\hline Group 2 - After operation & 93.08 & 9.04 & 99 & 99.00 & 71.00 \\
\hline sd - standard deviation; group 1 - Cross-Pin & \multicolumn{5}{c|}{; group 2 - EZLoc ${ }^{\mathrm{TM} .}}$.
\end{tabular}

Table 3 - KT- $1000^{\mathrm{TM}}$ arthrometer.

\begin{tabular}{c|c|c|c|c|c|c|c|c}
\hline Variable & Fixation & $\mathbf{N}$ & Mean & sd & Median & Minimum & Maximum & $\mathbf{P}$ \\
\hline Difference & Cross-Pin $^{\mathrm{TM}}$ & 25 & 2.16 & 1.95 & 2.00 & -2.00 & 5.00 & 0.703 \\
\hline & EZLOC $^{\mathrm{TM}}$ & 25 & 2.10 & 2.63 & 1.00 & -3.00 & 7.00 & \\
\hline
\end{tabular}

Table 4 - KT-1000 arthrometer.

\begin{tabular}{c|c|c|c|c|c}
\hline & & & \multicolumn{2}{|c|}{ Fixation } & \\
\hline & & & Cross-Pin $^{\text {TM }}$ & EZLoc $^{\text {TM }}$ & p \\
\hline Result & Good & $\mathrm{N}$ & 18 & 17 & \\
\hline & & $\%$ & $72.0 \%$ & $68.0 \%$ & 1.000 \\
\hline & Poor & $\mathrm{N}$ & 7 & 8 & \\
\hline & & $\%$ & $28.0 \%$ & $32.0 \%$ & \\
\hline
\end{tabular}

Chi-square test was used for comparisons between the two techniques.

After the SF-36 questionnaire had been applied, the results were put into the graph presented in Figure 3, divided between the domains of the SF-36. Only the domains of vitality and pain presented statistically significant differences between the two groups, and transfemoral fixation (Cross-Pin ${ }^{\mathrm{TM}}$ ) was superior in both of these. In the other domains (functional capacity, limitations and general, social, emotional and mental states), there were no statistical differences between the two types of fixation.

Two patients (one in each group) presented complications consisting of superficial skin infection at the tibial incision. These cases were treated with

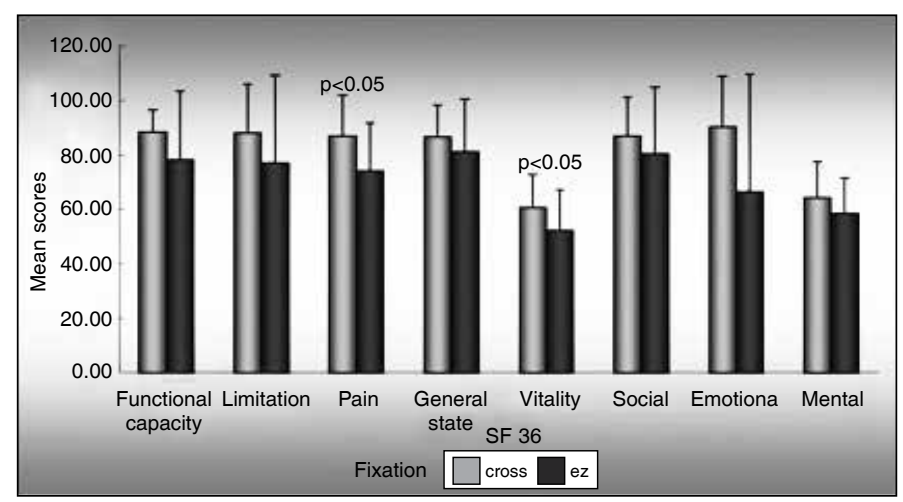

Figure 3-Graph showing data from SF-36 quality-of-life questionnaire. 
antibiotic therapy and local cleaning, and they evolved with clinical improvement. We believe that there was no relationship between the infectious process and the type of femoral fixation.

\section{DISCUSSION}

The ideal technique for fixation of grafts from the flexor tendons for ACL reconstruction remains a matter of controversy. In the recent literature, several techniques for femoral fixation have been reported, and these include use of interference screws, post suturing, extracortical fixation (Endobutton ${ }^{\mathrm{TM}}$, EZLoc $^{\mathrm{TM}}$ ) and transverse screws (Cross-Pin ${ }^{\mathrm{TM}}$ ). The greatest concern in using grafts from the flexor tendons is not in relation to their resistance but, rather, in relation to the efficiency of their fixation ${ }^{(12)}$.

A study on an animal model conducted by Rodeo et $\mathrm{al}^{(13)}$ showed that mechanical failure at the soft tissue-bone interface occurred within eight weeks of the reconstruction. The rehabilitation protocols following ACL reconstruction are generally aggressive, and therefore it is essential to establish fixation that is strong enough to resist the tension until the graft is biologically incorporated into the soft tissue during the initial rehabilitation period.

During this study, two different types of fixation were performed and compared: transverse screw (Cross-Pin $\left.{ }^{\mathrm{TM}}\right)$ and extracortical device (EZLoc $\left.{ }^{\mathrm{TM}}\right)$. The techniques chosen were especially advantageous, with the respective changes and differences in tunnel position in the femoral wall. Fixations using Cross-Pin ${ }^{\mathrm{TM}}$ performed in positions between 10 and 11 o'clock and between one and two o'clock may be compromised with the current fixation technique, which is lower on the femoral wall (anatomical reconstruction). In this technique, extracortical fixation devices present a lower chance of complications ${ }^{(14,15)}$.

In the present study, different positions of the femoral tunnel were not used, because the aim was just to compare the two types of fixation and not the two techniques (anatomical and traditional isometric).

Ahmad et $\mathrm{al}^{(16)}$ demonstrated in a specific laboratory study on femoral fixation of flexor tendons in the femur that among the four different types of fixation analyzed, femoral Cross-Pin ${ }^{\mathrm{TM}}$ and femoral Endobutton $^{\mathrm{TM}}$ had the best results. In the present study, no statistically significant difference was observed between the two groups after an average follow-up of 18 months, in relation to the Lysholm functional assessment.

The results obtained from our study in relation to the Lysholm functional assessment were the same as those in the literature, both for fixation with transverse screws and for fixation with extra-articular buttons. Independent of sex, age and associated lesions, the results shown were good or excellent.

In the evaluation with the KT-1000 ${ }^{\mathrm{TM}}$ arthrometer, the results from the non-operated and reconstructed knees were compared. Good results were found in 35 patients and poor results in 15. Among the latter, seven $(28 \%)$ were in the group with Cross-Pin ${ }^{\mathrm{TM}}$ and eight $(32 \%)$ were in the group with EZLoc ${ }^{\mathrm{TM}}$, and thus there was no statistically significant difference between the groups.

The poor results found in the evaluation using the KT-1000 ${ }^{\mathrm{TM}}$ were not observed in the assessments on the patients using the SF-36. Thus, the poor results did not appear to interfere with the patients' quality of life. Nevertheless, we believe that these poor results related to the use of a non-anatomical technique for ACL reconstruction, which corroborates the findings of Marchant et $\mathrm{al}^{(17)}$, in which a high incidence of non-anatomical reconstructions was found among the cases of ACL reconstruction. We do not believe that there was any relationship among the tibial or femoral fixations with the results found using the KT-1000 ${ }^{\mathrm{TM}}$, given that the three types of fixation (EZLoc ${ }^{\mathrm{TM}}$, Cross- Pin $^{\mathrm{TM}}$ and interference screw) are fully accepted in the literature as secure fixations.

In 2005, Harilainen et $\mathrm{al}^{(18)}$ published a randomized prospective study comparing Cross-Pin ${ }^{\mathrm{TM}}$ femoral fixation with interference screws and did not find any statistical difference relating to the KT-1000 ${ }^{\mathrm{TM}}$ findings between the two groups. Thus, their results were similar to those of the present study.

A randomized prospective study comparing femoral Cross-Pin ${ }^{\mathrm{TM}}$ and Endobutton ${ }^{\mathrm{TM}}$ for femoral fixation of the ACL using flexors, with two years of follow-up, did not find any statistical difference in relation to IKDC and KT-1000 ${ }^{\mathrm{TM}}$ among the 29 patients divided between the two groups ${ }^{(19)}$.

In the present study, 50 patients were assessed prospectively in a randomized manner, and the results encountered were similar to those of Price et $\mathrm{al}^{(19)}$, who also did not find any differences between the study groups regarding the KT-1000 ${ }^{\mathrm{TM}}$ test. 
The present study has an advantage over the study by Harilainen et $\mathrm{al}^{(18)}$, which was the only randomized prospective study comparing the extracortical technique with transfemoral fixation that we found. In our study, we additionally evaluated patient function by means of the Lysholm score and quality of life by means of the SF-36 questionnaire.

Although the subjective SF-36 quality-of-life assessment did not show any statistically significant difference regarding functional capacity, limitations or general, mental, social or emotional states, these similar results between the groups may be due to a limitation of our study relating to the short follow-up of only two years. It is possible that after longer follow-up among these patients, we will find different results.

In the SF-36 domain relating to pain, we observed that the patients in the group that underwent fixation using Cross-Pin ${ }^{\mathrm{TM}}$ presented better results than shown by those with EZLoc ${ }^{\mathrm{TM}}$, whereas it had been expected that the EZLoc ${ }^{\mathrm{TM}}$ group would have a better response, considering that it was not necessary to make an incision in the thigh and vastus lateralis muscle.
Surprisingly, these patients presented statistically significantly worse results than in the other group, which was subjected to greater and more aggressive surgical manipulation in the thigh musculature at the time of the femoral fixation. We were unable to find a logical explanation for this unexpected result, and not even in the literature.

Another domain in which we found a statistical difference favoring the group with Cross-Pin ${ }^{\mathrm{TM}}$ was vitality, but we were unable to explain the cause of this difference. Thus, it can be suggested that a greater length of follow-up is needed in order to obtain safer results.

In our view, new studies are necessary for better understanding of these differences to be achieved, along with greater length of follow up for these cases.

\section{CONCLUSION}

The techniques of transverse fixation (Cross-Pin ${ }^{\mathrm{TM}}$ ) and extracortical fixation (EZLoc $\left.{ }^{\mathrm{TM}}\right)$ in the femur, in surgical reconstructions of the ACL were shown to be efficient and safe for treating ACL injuries.

\section{REFERÊNCIAS}

1. Barrett GR, Papendick L, Miller C. Endobutton button endoscopic fixation technique in anterior cruciate ligament reconstruction. Arthroscopy. 1995;11(3):340-3.

2. Buelow JU, Siebold R, Ellermann A. A prospective evaluation of tunnel enlargement in anterior cruciate ligament reconstruction with hamstrings: extracortical versus anatomical fixation. Knee Surg Sports Traumatol Arthrosc. 2002;10(2):80-5.

3. Lajtai G, Schmiedhuber G, Unger F, Aitzetmüller G, Klein M, Noszian I, et al. Bone tunnel remodeling at the site of biodegradable interference screws used for anterior cruciate ligament reconstruction: 5-year follow-up. Arthroscopy. 2001;17(6):597-602.

4. L'Insalata JC, Klatt B, Fu FH, Harner CD. Tunnel expansion following anterior cruciate ligament reconstruction: a comparison of hamstring and patellar tendon autografts. Knee Surg Sports Traumatol Arthrosc. 1997;5(4):234-8.

5. Simonian PT, Monson JT, Larson RV. Biodegradable interference screw augmentation reduces tunnel expansion after ACL reconstruction. Am J Knee Surg. 2001 Spring;14(2):104-8.

6. Weiler A, Hoffmann RF, Bail HJ, Rehm O, Südkamp NP. Tendon healing in a bone tunnel. Part II: Histologic analysis after biodegradable interference fit fixation in a model of anterior cruciate ligament reconstruction in sheep. Arthroscopy. 2002;18(2):124-35.

7. Weiler A, Peine R, Pashmineh-Azar A, Abel C, Südkamp NP, Hoffmann RF. Tendon healing in a bone tunnel. Part I: Biomechanical results after biodegradable interference fit fixation in a model of anterior cruciate ligament reconstruction in sheep. Arthroscopy. 2002;18(2):113-23.

8. Clatworthy MG, Annear P, Bulow JU, Bartlett RJ. Tunnel widening in anterior cruciate ligament reconstruction: a prospective evaluation of hamstring and patella tendon grafts. Knee Surg Sports Traumatol Arthrosc. 1999;7(3):138-45.

9. Warden WH, Friedman R, Teresi LM, Jackson DW. Magnetic resonance imaging of bioabsorbale polylactic acid interference screws during the first 2 years after anterior cruciate ligament reconstruction. Arthroscopy. 1999;15(5):474-80.

10. Lajtai G, Humer K, Aitzetmüller G, Unger F, Noszian I, Orthner E. Serial mag-

netic resonance imaging evaluation of a bioabsorbable interference screw and the adjacent bone. Arthroscopy. 1999;15(5):481-8.

11. Matsumoto A, Howell SM. The EZLoc: A Simple, Rigid Femoral Fixation Device for a Soft Tissue Anterior Cruciate Ligament Graft. Tech Orthop. 2005;20(3):23844.

12. Höher J, Scheffler SU, Withrow JD, Livesay GA, Debski RE, Fu FH, et al. Mechanical behavior of two hamstring graft constructs for reconstruction of the anterior cruciate ligament. J Orthop Res. 2000;18(3):456-61.

13. Rodeo SA, Arnoczky SP, Torzilli PA, Hidaka C, Warren RF. Tendon-healing in a bone tunnel. A biomechanical and histological study in the dog. J Bone Joint Surg Am. 1993;75(12):1795-803.

14. Yamanaka M, Yasuda K, Tohyama H, Nakano H, Wada T. The effect of cyclic displacement on the biomechanical characteristics of anterior cruciate ligament reconstructions. Am J Sports Med. 1999;27(6):772-7.

15. Seil R, Rupp S, Krauss PW, Benz A, Kohn DM. Comparison of initial fixation strength between biodegradable and metallic interference screws and a press-fit fixation technique in a porcine model. Am J Sports Med. 1998;26(6):815-9.

16. Ahmad CS, Gardner TR, Groh M, Arnouk J, Levine WN. Mechanical properties of soft tissue femoral fixation devices for anterior cruciate ligament reconstruction. Am J Sports Med. 2004;32(3):635-40.

17. Marchant BG, Noyes FR, Barber-Westin SD, Fleckenstein C. Prevalence of nonanatomical graft placement in a series of failed anterior cruciate ligament reconstructions. Am J Sports Med. 2010;38(10):1987-96.

18. Harilainen A, Sandelin J, Jansson KA. Cross-pin femoral fixation versus metal interference screw fixation in anterior cruciate ligament reconstruction with hamstring tendons: results of a controlled prospective randomized study with 2-year follow-up. Arthroscopy. 2005;21(1):25-33.

19. Price R, Stoney J, Brown G. Prospective randomized comparison of endobutton versus cross-pin femoral fixation in hamstring anterior cruciate ligament reconstruction with 2-year follow-up. ANZ J Surg. 2010;80(3):162-5. 